\title{
Superplastic Grade Titanium Alloy: Comparative Evaluation of Mechanical Properties, Microstructure, and Fracture Behavior
}

\author{
K. V. Sudhakar and Ethan Wood \\ Montana Tech of the University of Montana, Butte, MT 59701, USA \\ Correspondence should be addressed to K. V. Sudhakar; kvsudhakar@mtech.edu
}

Received 21 April 2016; Revised 9 August 2016; Accepted 14 August 2016

Academic Editor: Hak Yong Kim

Copyright (C) 2016 K. V. Sudhakar and E. Wood. This is an open access article distributed under the Creative Commons Attribution License, which permits unrestricted use, distribution, and reproduction in any medium, provided the original work is properly cited.

In this investigation, static fracture, microstructure, and the mechanical behavior of SP-700 alloy (a superplastic grade) were evaluated and compared with two other titanium alloys. The comparisons were made in terms of suitably designed heat treatment cycles. The heat treatment cycles included annealing and a combination of solutionizing and aging treatments for all three alloys. Tensile properties were determined using MTS Landmark Servohydraulic Test System. Tensile tested samples' fracture surfaces were investigated with LEO-VP SEM instrument. Ti-15-3-3-3 alloy exhibited relatively a higher combination of strength and ductility in comparison to the other two alloys. All three types of titanium alloys demonstrated a very good level of tensile strength and ductility suitable for applications in military and biomedical fields.

\section{Introduction}

The continuous need for strong lightweight implant materials has produced several high quality/performing metal alloys. Stainless steel was the first metallic biomaterial to be used and later titanium and its alloys were used for bone plates and hip joints [1]. The beta phase titanium alloys have gained significant interest in the last few decades [2]. It is well known that the difference between the elastic modulus of the bone and the synthetic biomaterial causes stress shielding effect in bone. This effect wears away the bone and causes the implant to loosen leading to premature failure. The elastic modulus of bone is about $30 \mathrm{GPa}$ and that of stainless steel, cobalt-chromium, and titanium are 200,230 , and $127 \mathrm{MPa}$, respectively. The modulus of beta phase titanium alloys can be reduced to as low as $40 \mathrm{GPa}$ with appropriate alloying additions [3]. SP-700 alloy (Ti-4.5Al-3V-2Mo-2Fe alloy) is an alpha-beta titanium alloy that is beta-rich with a fine microstructure. SP-700 alloy is superplastically formed into several useful components for applications in aircraft and aerospace parts, working tools, automobile parts, and mountain climbing equipment in addition to medical applications.
Ti-15-3-3-3 alloy [4] was developed basically for military applications. It has high strength with good cold formability. The alloy SP-700 was developed to improve hot workability and mechanical properties over the Ti-6Al-4V alloy. SP-700 alloy has $4.5 \% \mathrm{Al}, 3 \% \mathrm{~V}, 2 \% \mathrm{Mo}$, and $2 \% \mathrm{Fe}$ elements that provide good hardenability and fatigue strength [5]. BetaC [6] was basically developed to replace the Ti-13-11-3 alloy grade. In beta titanium alloys, the heat treatment cycles are alloy specific because of their wide range of alloying elements. In highly stabilized beta alloys, it is normally difficult to achieve the desired distribution of alpha phase in the beta matrix with just one aging cycle. A lower temperature preage is typically performed to get a better distribution of alpha phase $[2,7]$. Beta titanium alloys form a metastable beta phase when quenched from the beta transus temperature. High strength levels can be achieved in beta titanium alloys by varying aging temperature and time. During aging, the alpha particles preferentially precipitate along the beta grain boundaries $[2,7-10]$.

The goal of this study is to evaluate microstructure, static fracture, and tensile properties of SP-700 titanium alloy as a function of heat treatment cycles and compare these 
TABle 1: Heat treatment cycle for the 1st set of Ti-15-3-3-3 alloy samples.

\begin{tabular}{lccc}
\hline \multicolumn{4}{c}{ Ti-15-3-3-3 } \\
& $\begin{array}{c}\text { Temperature } \\
\left({ }^{\circ} \mathrm{C}\right)\end{array}$ & $\begin{array}{c}\text { Time } \\
(\mathrm{hr} .)\end{array}$ & Cooling method \\
\hline Annealing & 800 & 0.25 & Air \\
Solution treatment & 800 & 0.25 & Air \\
& 510 & 24 & Air \\
Aging (AG) & 550 & 24 & Air \\
& 590 & 24 & Air \\
\hline
\end{tabular}

TABLE 2: Heat treatment cycle for the 2nd set of Ti-15-3-3-3 alloy samples.

\begin{tabular}{lccc}
\hline \multicolumn{4}{c}{ Ti-15-3-3-3 } \\
& $\begin{array}{c}\text { Temperature } \\
\left({ }^{\circ} \mathrm{C}\right)\end{array}$ & $\begin{array}{c}\text { Time } \\
(\mathrm{hr})\end{array}$ & Cooling method \\
\hline Annealing & 800 & 0.25 & Air \\
Solution treatment & 800 & 0.25 & Air \\
& 450 & 24 & Air \\
Aging (AG) & 515 & 24 & Air \\
& 625 & 24 & Air \\
\hline
\end{tabular}

characteristics with the other two alloys of titanium used typically for military and biomedical applications.

\section{Materials and Methods}

2.1. Materials. The materials used in this investigation were alpha-beta and beta phase titanium alloys. Three different beta phase titanium alloys were used, namely, Ti-15-3-3-3, SP-700, and Beta-C. The Ti-15-3-3-3 and SP-700 alloys were in sheet metal form with thickness $1.28 \mathrm{~mm}$ and $2.78 \mathrm{~mm}$, respectively. The Beta- $\mathrm{C}$ alloy was in rod form having $19.05 \mathrm{~mm}$ in diameter. The alloy composition of Ti-15-3-3-3 alloy is titanium with $15 \% \mathrm{~V}, 3 \% \mathrm{Al}, 3 \% \mathrm{Cr}$, and $3 \% \mathrm{Sn}$. The alloy composition of SP-700 alloy is titanium with $4.5 \% \mathrm{Al}$, $3 \% \mathrm{~V}, 2 \% \mathrm{Mo}$, and $2 \% \mathrm{Fe}$ and the Beta-C alloy contained 3\% $\mathrm{Al}, 8 \% \mathrm{~V}, 6 \% \mathrm{Cr}, 4 \% \mathrm{Mo}, 4 \% \mathrm{Zr}$, and balance titanium $[11,12]$.

2.2. Heat Treatment Cycles. Specific heat treatment cycles were developed for each of the three titanium alloys. Heat treatments were carried out using a Thermo Scientific Thermolyne furnace with a $\varepsilon$ Eurotherm 2416 controller. The temperature was monitored with a HH11A $\Omega$ omega thermocouple. The heat treatment cycle details for the 1st and 2nd sets of Ti-15-3-3-3 samples are provided in Tables 1 and 2 , respectively.

The aging temperatures for the 2nd set of Ti-15-3-3-3 samples were adjusted from the 1st set with a goal of achieving better combination of strength and ductility.

The heat treatment details for the Beta-C alloy are demonstrated in Table 3 .

The heat treatment cycle details for the 1st and 2nd sets of SP-700 alloy are shown in Tables 4 and 5, respectively.
TABLE 3: Heat treatment cycle for the Beta-C tensile samples.

\begin{tabular}{lccc}
\hline & \multicolumn{2}{c}{ Beta-C } & \\
& $\begin{array}{c}\text { Temperature } \\
\left({ }^{\circ} \mathrm{C}\right)\end{array}$ & $\begin{array}{c}\text { Time } \\
(\mathrm{hr})\end{array}$ & Cooling method \\
\hline Annealing & 800 & 0.5 & Air \\
Solution treatment & 850 & 1 & Air \\
& 455 & 24 & Air \\
Aging (AG) & 495 & 24 & Air \\
& 540 & 24 & Air \\
\hline
\end{tabular}

TABLE 4: Heat treatment cycle for the 1st set of SP-700 tensile samples.

\begin{tabular}{lccc}
\hline & \multicolumn{2}{c}{ SP-700 } & \\
& $\begin{array}{c}\text { Temperature } \\
\left({ }^{\circ} \mathrm{C}\right)\end{array}$ & $\begin{array}{c}\text { Time } \\
(\mathrm{hr})\end{array}$ & Cooling method \\
\hline Annealing & 825 & 1 & Air \\
Solution treatment & 825 & 1 & Air \\
& 450 & 6 & Air \\
Aging (AG) & 525 & 6 & Air \\
& 600 & 6 & Air \\
\hline
\end{tabular}

TABLE 5: Heat treatment cycle for the 2nd set of SP-700 tensile samples.

\begin{tabular}{lccc}
\hline & \multicolumn{2}{c}{ SP-700 } & \\
& $\begin{array}{c}\text { Temperature } \\
\left({ }^{\circ} \mathrm{C}\right)\end{array}$ & $\begin{array}{c}\text { Time } \\
(\mathrm{hr})\end{array}$ & Cooling method \\
\hline Annealing & 700 & 1 & Air \\
Solution treatment & 800 & 0.75 & Air \\
& 420 & 6 & Air \\
Aging (AG) & 485 & 6 & Air \\
& 630 & 6 & Air \\
\hline
\end{tabular}

It may be noted that the cooling method (air) used for all the three titanium alloys is the same, as can be seen in Tables $1-5$.

2.3. Tensile Testing. The tensile tests were performed on a MTS Landmark Servohydraulic Test System, as per the ASTM E8/E8M standard. The data collection speed was $10 \mathrm{~Hz}$ and the test speed was $0.042 \mathrm{~mm}$ per second. Figure 1 is a schematic drawing of the Ti-15-3-3-3 and SP-700 tensile flat test specimens. The tensile specimens of Ti-15-3-3-3 and SP700 alloys had the same dimensions except for thickness and they were $1.28 \mathrm{~mm}$ and 2.78 thick, respectively. The computer recorded the stress and strain values during the test for every 0.1 second. Figure 2 is a schematic drawing of the Beta-C round tensile specimen. The diameter of the reduced section of the Beta-C specimen was $8.89 \mathrm{~mm}$, as shown in Figure 2 . Figure 3 shows strain gage attachments to Beta- $C$ tensile specimens before tensile testing. 


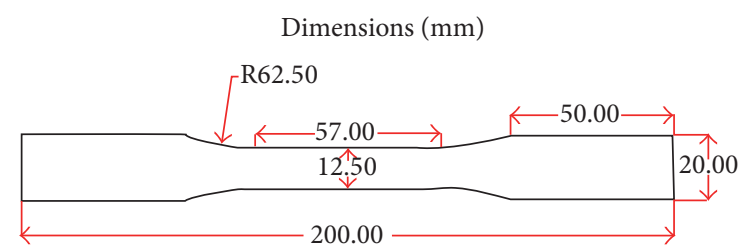

FIgURE 1: Schematic of the flat Ti-15-3-3-3 and SP-700 tensile specimens.

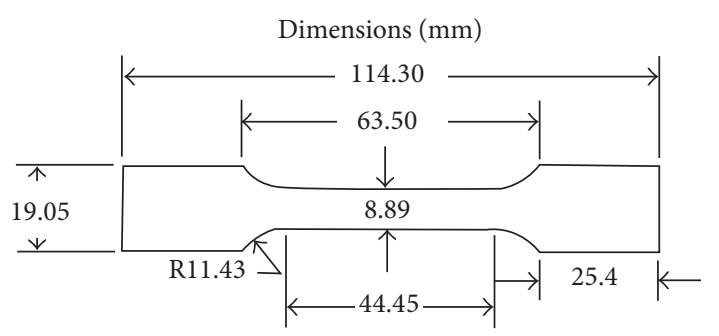

FIGURE 2: Schematic of the round Beta-C tensile specimen.

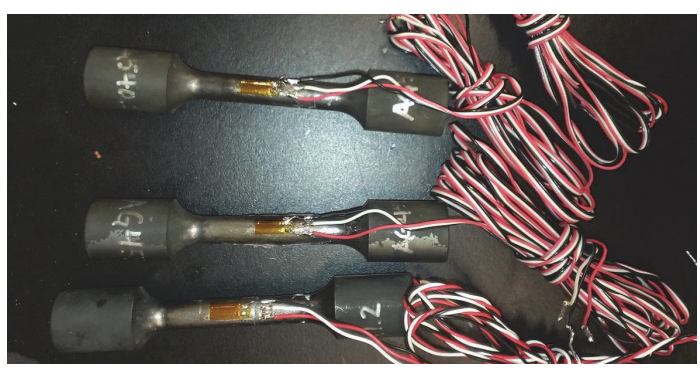

Figure 3: Beta-C tensile specimens with strain gauges attached.

\section{Results and Discussion}

\subsection{Tensile Properties}

3.1.1. Tensile Properties of Ti-15-3-3-3 Alloy. The first set of Ti-15-3-3-3 samples demonstrated an increase in strength from $772 \mathrm{MPa}$ (for the annealed one) to $1169 \mathrm{MPa}$ (for the aged-AG510 sample). As expected, the corresponding ductility (in terms of elongation) decreased from $34 \%$ to $12 \%$. The sample AG510 provided the best strength, but with the lowest ductility. Among the second set of Ti-15-33-3 alloy specimens, the sample AG450 exhibited the best strength at $1334 \mathrm{MPa}$. Overall, the strength decreased and the ductility increased with the increase in aging temperature for both sets of samples. Figures 4 and 5 demonstrate the stress-strain behavior and UTS values, respectively. The ideal aging temperature seems to be about $550^{\circ} \mathrm{C}$ (AG550) for obtaining a good combination of strength and ductility. At this temperature, the strength increased from about $800 \mathrm{MPa}$ to $998 \mathrm{MPa}$ with $23 \%$ ductility. So, AG550 treatment exhibited the best balance of mechanical properties desired for a metallic biomaterial.

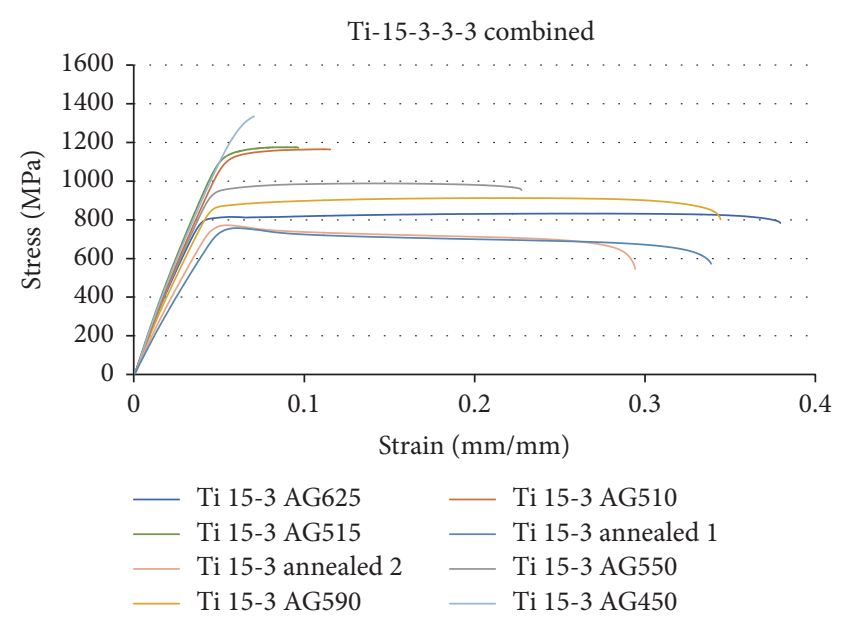

Figure 4: Stress-strain curves for both sets of the Ti-15-3-3-3 samples.

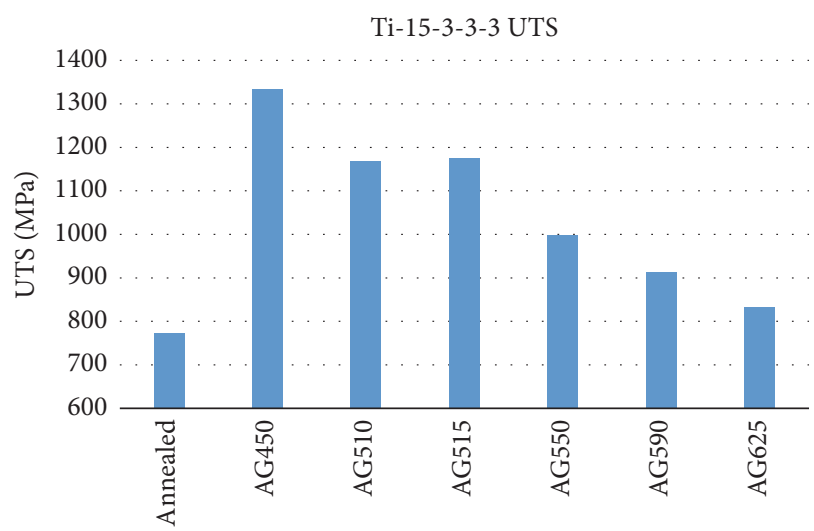

FIgURE 5: Ultimate tensile strength for the Ti-15-3-3-3 samples.

3.1.2. Tensile Properties of SP-700 Alloy. In the first set of SP-700 alloy specimens, the annealed condition produced strength at $978 \mathrm{MPa}$ with the best ductility ( $13 \%$ elongation). AG450 sample showed a reduction in strength as well as in ductility ( $4 \%$ elongation). AG525 sample exhibited a significant increase in strength (978 $\mathrm{MPa}$ to $1168 \mathrm{MPa})$ with a large reduction in ductility (13\% to 5\% elongation). AG600 sample had strength of $1142 \mathrm{MPa}$, while retaining better ductility than AG525 ( $\sim 10 \%$ elongation compared to $5 \%$ elongation).

In the second set of SP-700 samples, it provided a slight increase in strength (in comparison to the 1st set) and a significant increase in ductility. The low temperature age, AG420, resulted in low strength and low ductility ( $5 \%$ elongation). The medium temperature age, AG485, provided a small increase in strength (1031 MPa to $1093 \mathrm{MPa})$ with a significant decrease in ductility ( $27 \%$ to $5 \%$ elongation). AG630 sample provided an unchanged strength value with a marginal increase ( $27 \%$ to $30 \%$ elongation) in ductility. The stress-strain curves and the UTS for the 1st and 2nd sets of SP700 samples are demonstrated in Figures 6 and 7, respectively. 


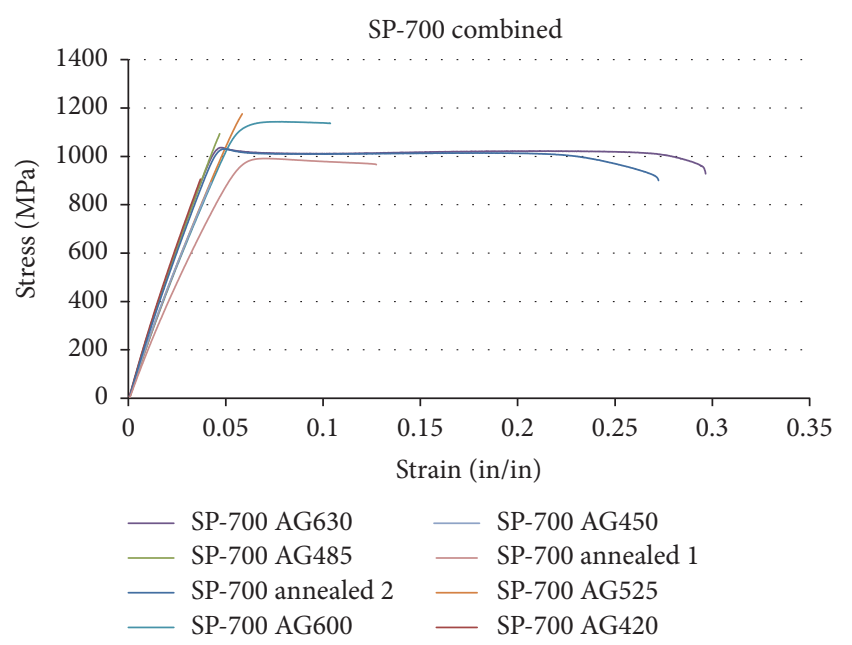

FIGURE 6: Comparison of stress-strain curves for SP-700 tensile samples.

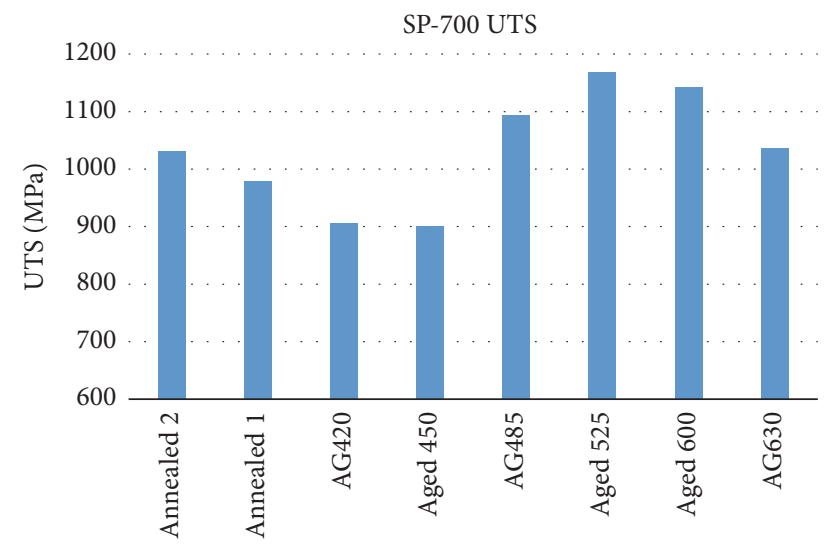

FIGURE 7: Ultimate tensile strength for the SP-700 tensile samples.

3.1.3. Tensile Properties of Beta-C Alloy. The stress-strain curves and UTS values for the Beta-C samples are shown in Figures 8 and 9, respectively. Samples AG455 and AG495 demonstrated similar strengths, but the former exhibited relatively a higher ductility ( $\sim 23 \%$ from $\sim 19 \%$ elongation). AG540 showed almost the same level of strength with a relative decrease in ductility ( $37 \%$ to $27 \%$ elongation). AG455 sample showed strength at $964 \mathrm{MPa}$ with a very good level of ductility ( $23 \%$ elongation).

3.2. Comparison of Tensile Properties of All Three Titanium Alloys. The ultimate tensile strength of all three titanium alloys are compared and summarized in Figure 10. The mechanical properties can be significantly improved by using a duplex aging process [13-15].

3.3. Optical Microscopy. A Leica DM750P optical microscope, paired with Leica application suite software was used to study the microstructure of the titanium alloys. The samples were etched with Kroll's Reagent that consists of $2 \%$ hydrofluoric acid, $6 \%$ nitric acid, and $92 \%$ distilled water.

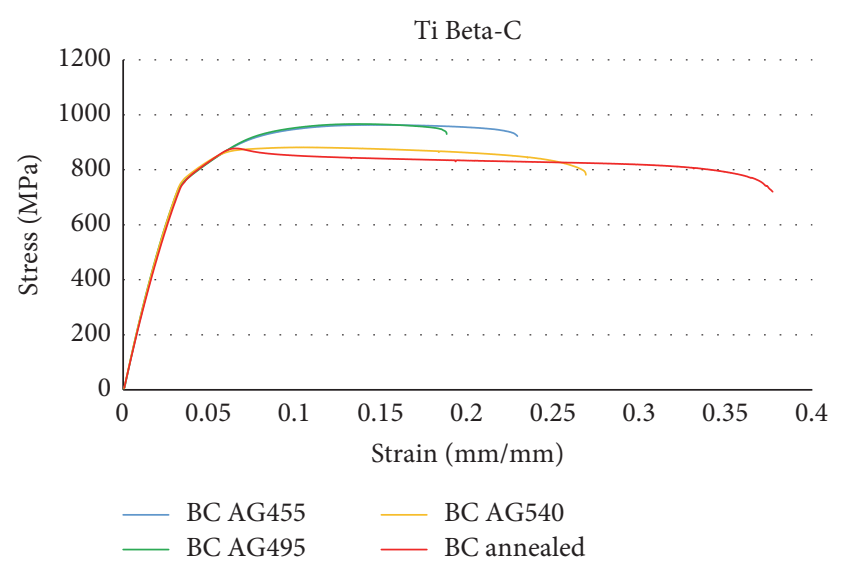

FIGURE 8: Stress-strain curves for the Beta-C tensile samples.

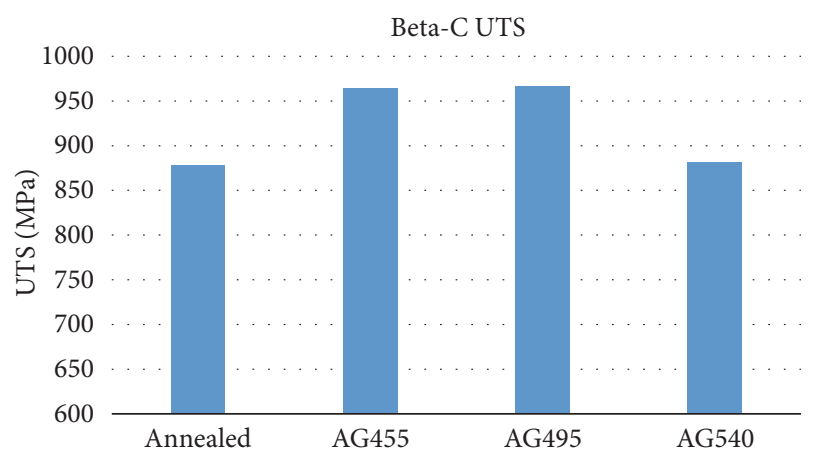

FIGURE 9: Ultimate tensile strength for the Beta-C tensile samples.

3.3.1. Microstructure Characterization of Ti-15-3-3-3 Alloy. The annealed Ti-15-3-3-3 sample exhibited large equiaxed grains of beta phase titanium (Figure 11).

The crystals of alpha precipitates in the AG550 sample (Figure 12) are relatively small and evenly dispersed in comparison to that in AG590 sample (Figure 13). The finer grain structure of AG550 sample produced better strength than the AG590 sample that contained relatively larger crystals of the alpha phase. It is evident that the size of the alpha crystals increases with increasing aging temperature. The growth rate of the alpha phase increases with the greater amount of solute available (at higher aging temperatures) for the formation of the precipitate.

3.3.2. Microstructure Characterization of SP-700 Alloy. Figures 14 and 15 reveal the microstructures for the SP-700 samples. The SP-700 samples have an extremely small grain size in comparison to Ti-15-3-3-3 and Beta-C alloys. The average grain size of the annealed Ti-15-3-3-3 and Beta-C is about $50 \mu \mathrm{m}$ as opposed to about $2 \mu \mathrm{m}$ for the SP-700 alloy. The fine grain sized SP-700 (a super plastic grade) alloys demonstrated a simultaneous increase in strength and ductility. Superplasticity is a grain size dependent phenomenon [16]. This is attributed to the slip flexibility factor. Slip flexibility is facilitated by a fine grain size. As a result, a more homogeneous and uniform gross plasticity occurs 


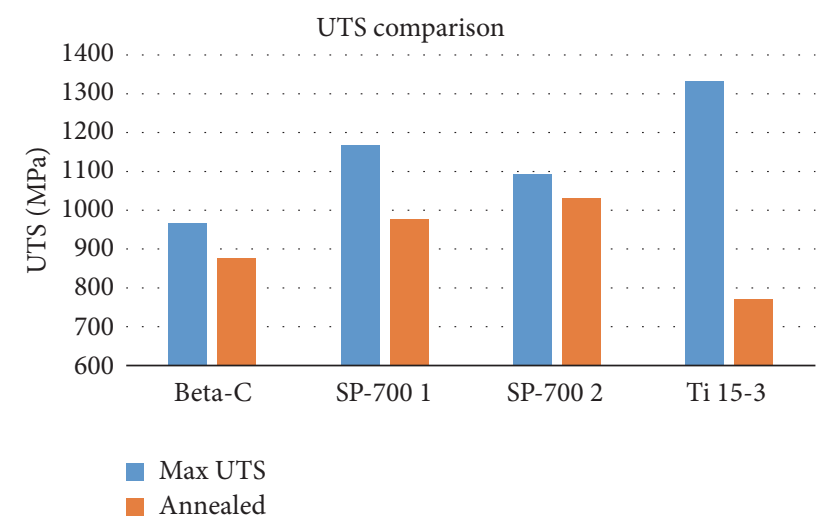

FIgURE 10: Comparison of UTS among all three titanium tensile samples.

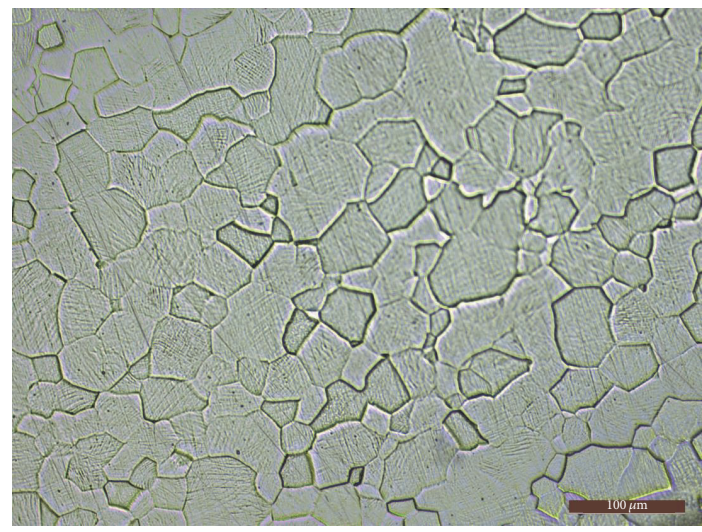

FIGURE 11: Microstructure for the annealed Ti-15-3-3-3 sample. Etched with Kroll's Reagent.

over the entire polycrystalline material. Another explanation is that, in fine grain-sized alloys, the deformation behavior of the grain boundary dominates over the bulk deformation behavior resulting in higher ductility. To emphasize, the fine grain structure of SP-700 alloy increases its strength but is not detrimental its toughness or ductility.

3.3.3. Microstructure Characterization of Beta-C Alloy. Microstructure of the annealed Beta-C sample with equiaxed grains is shown in Figure 16. The sample in the annealed condition contains no alpha precipitates. In Figure 17 (for AG455) and Figure 18 (for AG540), precipitation of alpha particles along the grain boundaries can be seen clearly. AG455 sample shows intergranular alpha precipitates. The incomplete distribution of alpha particles throughout the grain structures of AG455 and AG540 samples was caused by the preferential nucleation at the grain boundaries. As a result, the tensile strength of the samples did not increase as much as could be expected.

To summarize, the microstructure of Ti-15-3-3-3 sample AG550 that demonstrated the most desirable combination of strength and ductility. This is attributed to the fine crystals of alpha that grew during the aging process. It is proposed that these alpha crystals in the beta matrix provide the

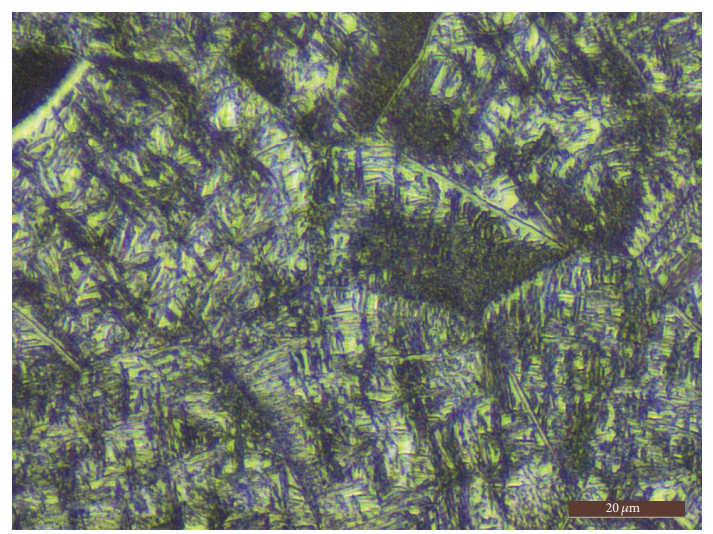

FIGURE 12: Microstructure of the Ti-15-3-3-3 sample aged at $550^{\circ} \mathrm{C}$. Etched with Kroll's Reagent.

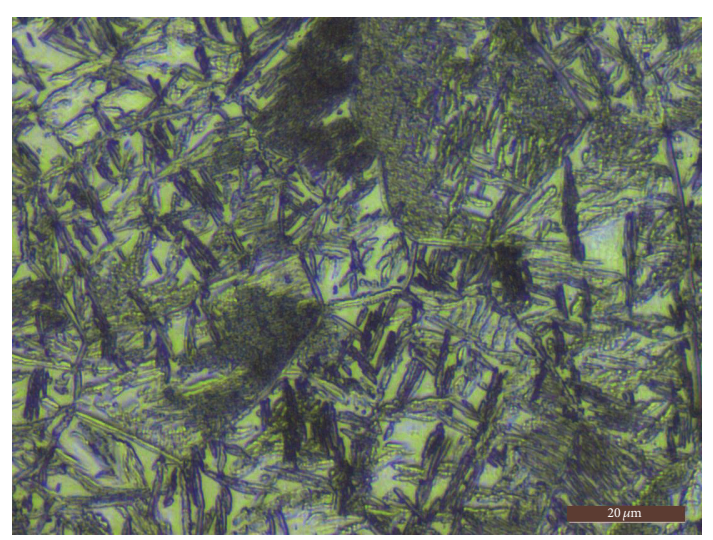

FIGURE 13: Microstructure for the Ti-15-3-3-3 sample aged at $590^{\circ} \mathrm{C}$. Etched with Kroll's Reagent.

increase in strength as wells as provide a more tortuous path for crack propagation thereby increasing toughness, as well. A high strength and toughness (UTS of $1000 \mathrm{MPa}$ and $23 \%$ elongation) combination makes Ti-15-3-3-3 alloy an excellent candidate for biomedical applications. It is well known that the extremely fine grain structure of SP-700 provides good strength without losing toughness. Because of its fine structure, the annealed condition provides sufficient strength and ductility for biomedical use (UTS of $1000 \mathrm{MPa}$ and 27\% elongation). An incomplete precipitation of intergranular alpha phase in the microstructure of Beta-C sample still provided higher mechanical properties. However, the use of a duplex aging process will allow for a more complete nucleation of intergranular beta prime phase and the growth of the alpha phase in the beta matrix. Duplex aging process will further improve the tensile strength $(\sim 1000$ to $\sim 1300 \mathrm{MPa}$ ) [13], fatigue strength, and fracture toughness of the Beta-C alloy $[17,18]$.

3.4. Fractography. Titanium fractured samples were examined using a SEM LEO 1430VP scanning electron microscope. Figure 19 demonstrates a typical ductile fracture for the SP700 AG525 sample. 


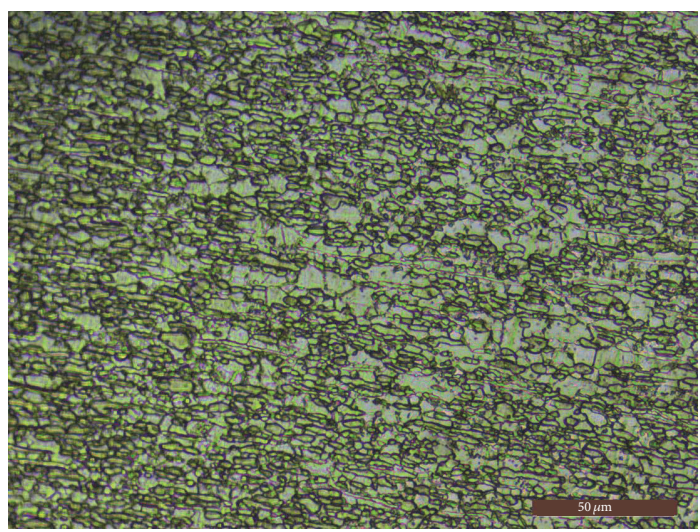

FIGURE 14: Microstructure for the 1st annealed SP-700 sample. Etched with Kroll's Reagent.

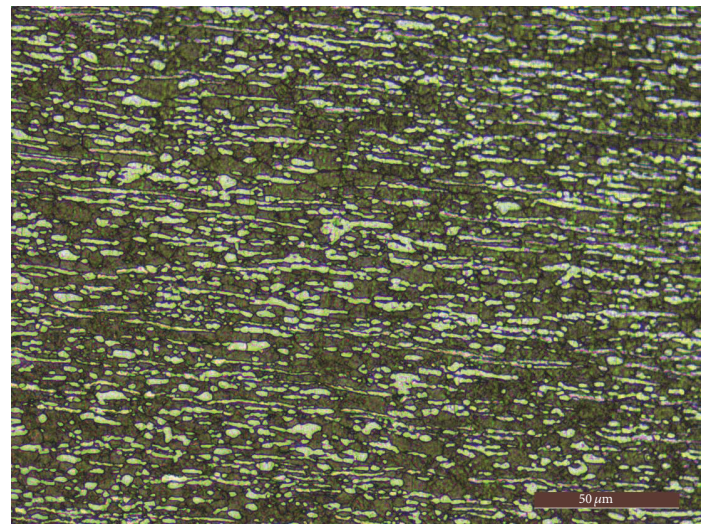

FIgURE 15: Microstructure for the SP-700 sample aged at $525^{\circ} \mathrm{C}$. Etched with Kroll's Reagent.

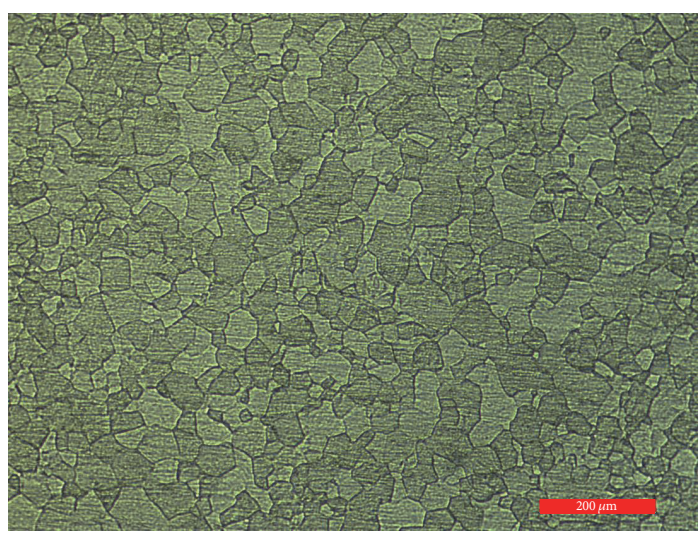

FIGURE 16: Microstructure of the annealed Beta-C sample. Etched with Kroll's Reagent.

\section{Conclusions}

(i) The microstructure of the Ti-15-3-3-3 sample AG550 has fine crystals of alpha that grew during the aging process. These alpha crystals in the beta matrix are

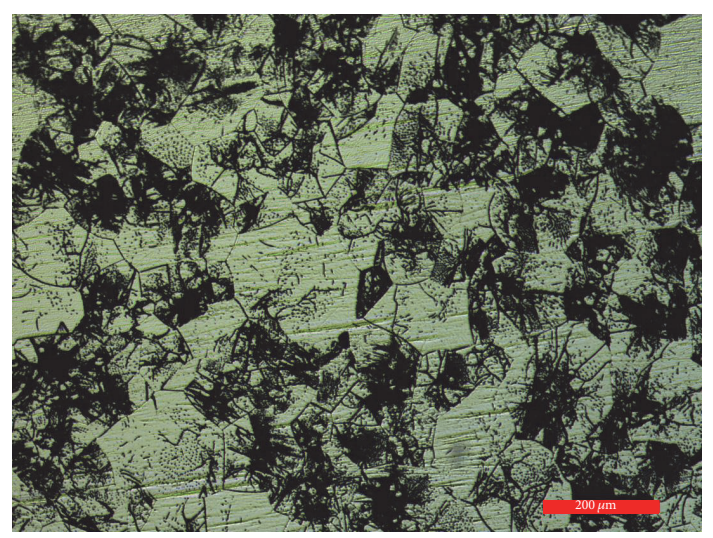

Figure 17: Microstructure for the Beta-C sample aged at $455^{\circ} \mathrm{C}$. Etched with Kroll's Reagent.

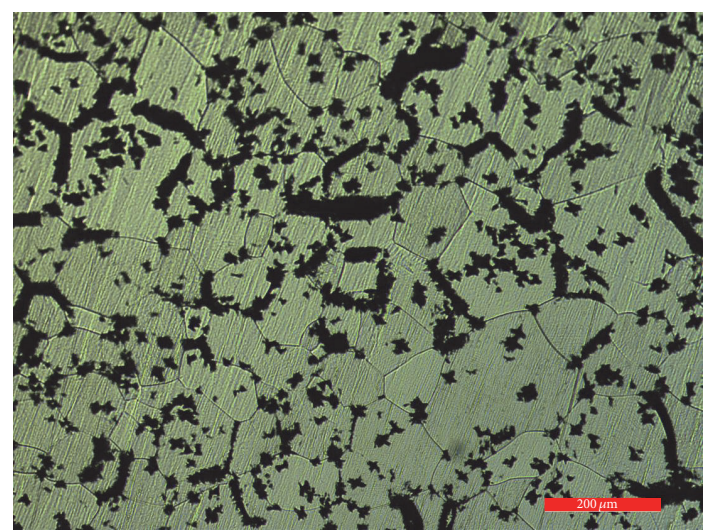

Figure 18: Microstructure of the Beta-C sample aged at $540^{\circ} \mathrm{C}$. Etched with Kroll's Reagent.

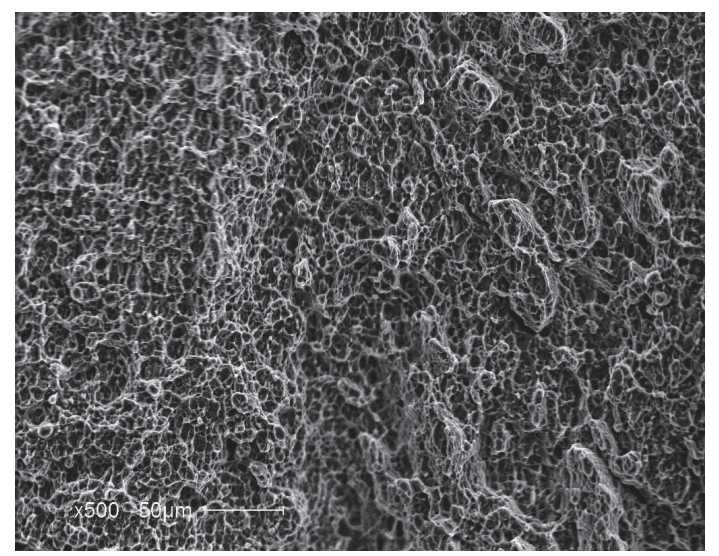

FIGURE 19: Fracture morphology of the SP-700 sample aged at $525^{\circ} \mathrm{C}$.

responsible for the increase in strength and toughness.

(ii) It is determined that the extremely fine grain structure of the annealed SP-700 provides good strength $(1000 \mathrm{MPa})$ in the alloy without reduction in toughness. 
(iii) The best set of mechanical properties, though with an incomplete precipitation of intergranular alpha phase, was demonstrated for the microstructure of Beta-C alloy that was aged at $455^{\circ} \mathrm{C}$.

(iv) The fracture analysis of the SP-700 alloy including the other two titanium alloys demonstrated dimple features indicative of excellent toughness in all three titanium alloys.

\section{Disclosure}

The views and conclusions contained in this document are those of the authors and should not be interpreted as representing the official policies, either expressed or implied, of the Army Research Laboratory or the US Government. The US Government is authorized to reproduce and distribute reprints for government purposes notwithstanding any copyright notation herein.

\section{Competing Interests}

The authors declare that they have no competing interests.

\section{Acknowledgments}

Research was sponsored by the Army Research Laboratory and was accomplished under Cooperative Agreement no. W911NF-15-2-0020.

\section{References}

[1] S. Ramakrishna, M. Ramalingam, T. S. Kumar, and W. O. Soboyejo, Biomaterials: A Nano Approach, CRC Press, Boca Raton, Fla, USA, 2010.

[2] R. Santhosh, M. Geetha, V. K. Saxena, and M. Nageswararao, "Studies on single and duplex aging of metastable beta titanium alloy Ti-15V-3Cr-3Al-3Sn," Journal of Alloys and Compounds, vol. 605, pp. 222-229, 2014.

[3] M. Niinomi, "Mechanical biocompatibilities of titanium alloys for biomedical applications," Journal of the Mechanical Behavior of Biomedical Materials, vol. 1, no. 1, pp. 30-42, 2008.

[4] H. W. Rosenberg, "Ti 15-3-3-3: a new cold-formable sheet titanium alloy," Journal of Materials, vol. 35, no. 11, pp. 30-34, 1983.

[5] A. Ogawa, M. Niikura, C. Ouchi, K. Minikawa, and M. Yamada, "Development and applications of titanium alloy SP-700 with high formability," Journal of Testing and Evaluation, vol. 24, no. 2, pp. 100-109, 1996.

[6] G. Welsch, R. Boyer, and E. W. Collings, "Ti-3Al-8V-6Cr4Mo-4Zr (beta C)," in Materials Properties Handbook: Titanium Alloys, p. 797, ASM International, 1993.

[7] G. Lutjering and J. C. Williams, Eds., Titanium, Springer, Berlin, Germany, 2nd edition, 2007.

[8] J. Ma and Q. Wang, "Aging characterization and application of Ti-15-3 alloy," Materials Science and Engineering: A, vol. 243, no. 1-2, pp. 150-154, 1998.

[9] I. Weiss and S. L. Semiatin, "Thermomechanical processing of beta titanium alloys-an overview," Materials Science and Engineering: A, vol. 243, no. 1-2, pp. 46-65, 1998.
[10] C. Sauer and G. Luetjering, "Thermo-mechanical processing of high strength $\beta$-titanium alloys and effects on microstructure and properties," Journal of Materials Processing Technology, vol. 117, no. 3, pp. 311-317, 2001.

[11] H. J. Rack and J. I. Qazi, "Titanium alloys for biomedical applications," Materials Science and Engineering C, vol. 26, no. 8, pp. 1269-1277, 2006.

[12] R. Boyer, G. Welsch, and E. W. Collings, Materials Properties Handbook: Titanium Alloys, ASM International, Materials Park, Ohio, USA, 1994.

[13] S. Ankem and C. A. Greene, "Recent developments in microstructure/property relationships of beta titanium alloys," Materials Science and Engineering A, vol. 263, no. 2, pp. 127-131, 1999.

[14] D. Kuroda, M. Niinomi, M. Morinaga, Y. Kato, and T. Yashiro, "Design and mechanical properties of new $\beta$ type titanium alloys for implant materials," Materials Science and Engineering A, vol. 243, no. 1-2, pp. 244-249, 1998.

[15] B. Gunawarman, M. Niinomi, T. Akahori, T. Souma, M. Ikeda, and $\mathrm{H}$. Toda, "Mechanical properties and microstructures of low cost $\beta$ titanium alloys for healthcare applications," Materials Science and Engineering: C, vol. 25, no. 3, pp. 304-311, 2005.

[16] S. N. Patankar, J. P. Escobedo, D. P. Field et al., "Superior superplastic behavior in fine-grained Ti-6Al-4V sheet," Journal of Alloys and Compounds, vol. 345, no. 1-2, pp. 221-227, 2002.

[17] E. Eisenbarth, D. Velten, M. Müller, R. Thull, and J. Breme, "Biocompatibility of $\beta$-stabilizing elements of titanium alloys," Biomaterials, vol. 25, no. 26, pp. 5705-5713, 2004.

[18] M. Chang, C. Luo, M. Huang, K. Ou, L. Lin, and H. Cheng, "High-temperature microstructural characteristics of a novel biomedical titanium alloy," Journal of Alloys and Compounds, vol. 499, no. 2, pp. 171-175, 2010. 

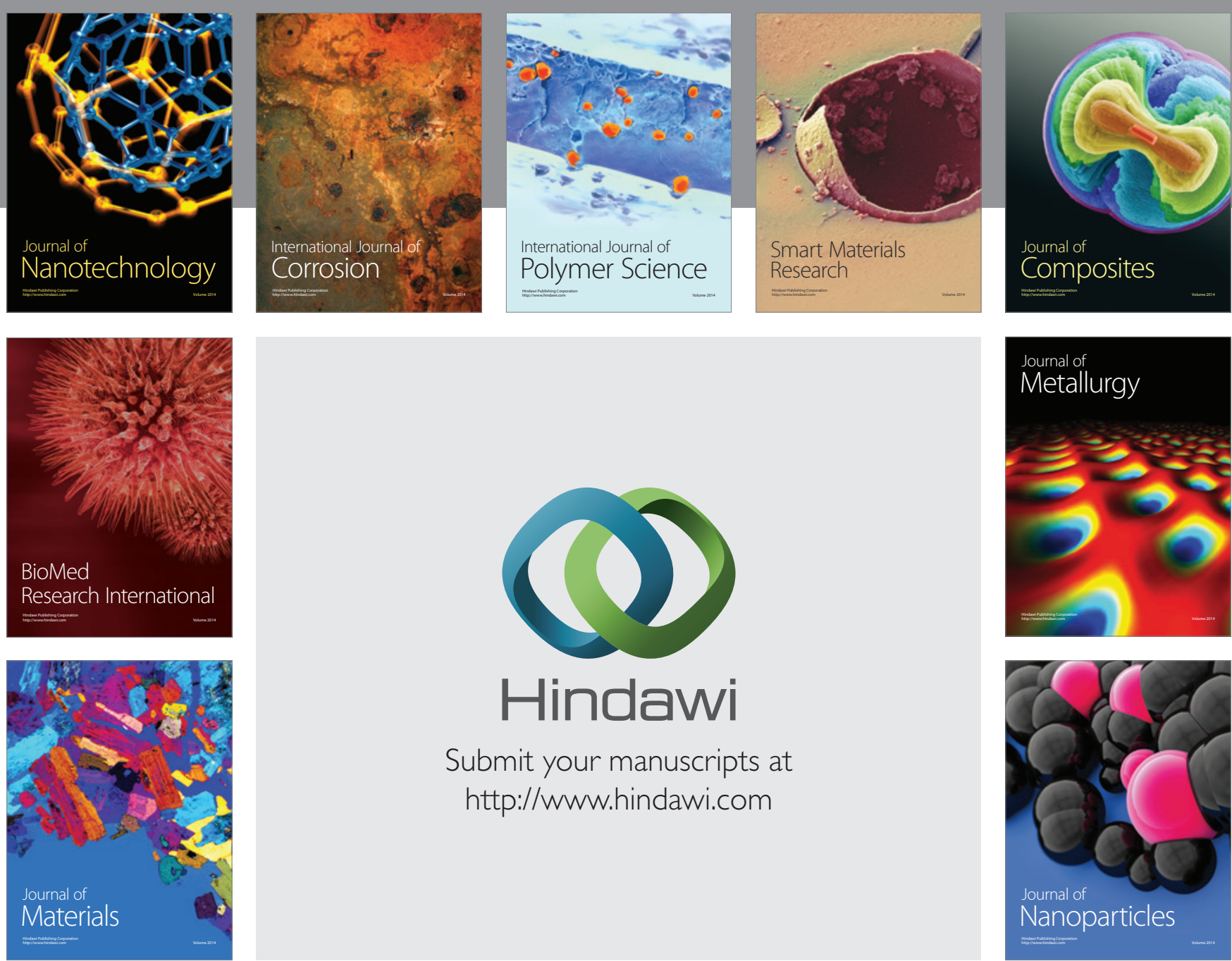

\section{Hindawi}

Submit your manuscripts at

http://www.hindawi.com

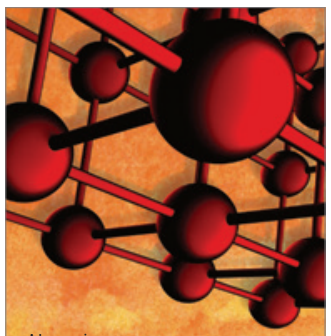

Materials Science and Engineering
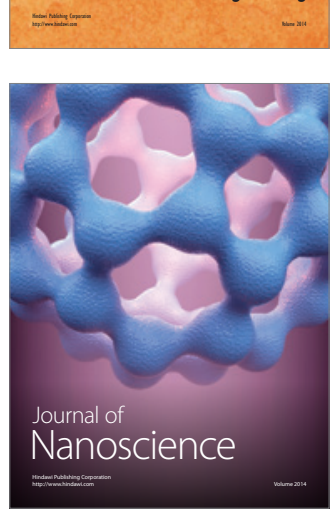
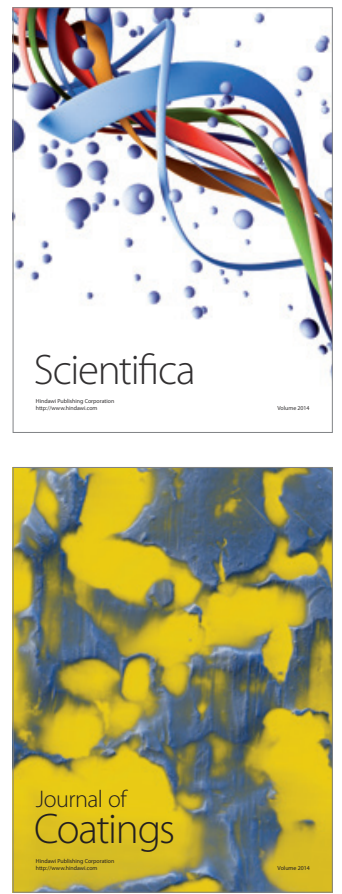
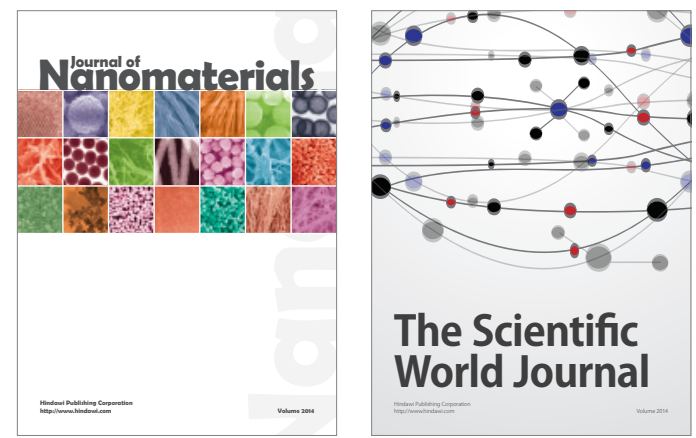

The Scientific World Journal
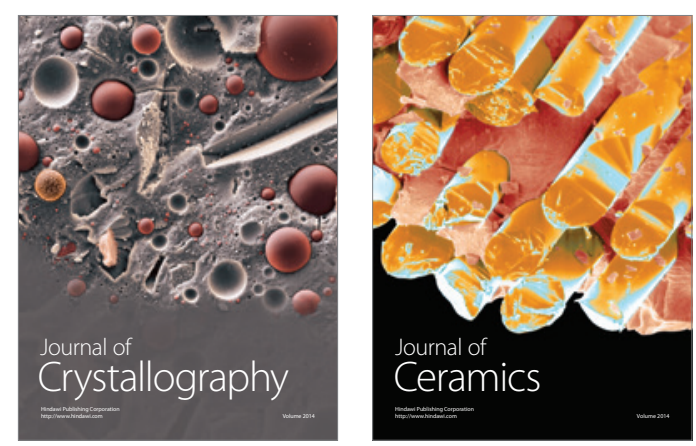
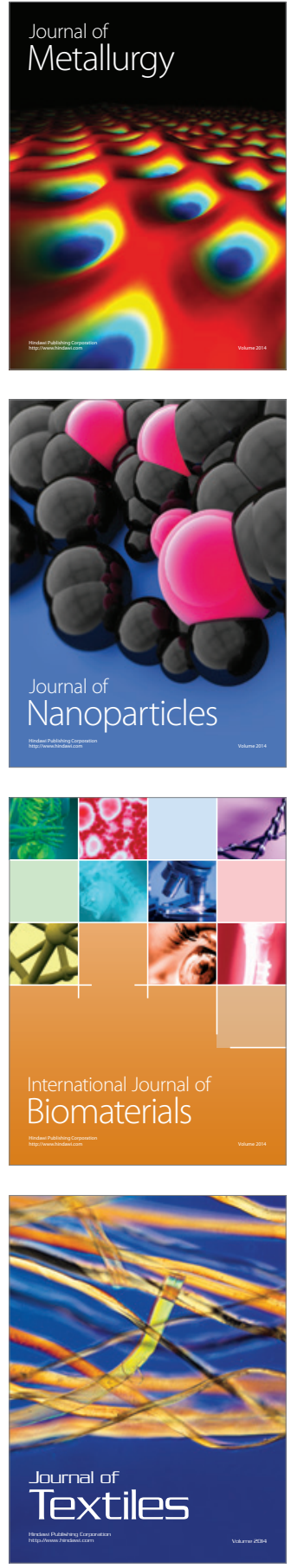